\section{artelogie}

\section{Artelogie}

Recherche sur les arts, le patrimoine et la littérature de l'Amérique latine

10 | 2017

Après le paysage : l'art, l'inscription et la représentation de la nature en Amérique latine aujourd'hui

\title{
Entretien avec Leonel Luna. Paisaje Americano, exposición de Leonel Luna
}

Pabellón de las Artes, Universidad Católica Argentina, Buenos Aires, 07/09/16 al 09/10/16

\section{Marta Penhos}

\section{OpenEdition}

Journals

Edición electrónica

URL: http://journals.openedition.org/artelogie/898

DOI: 10.4000/artelogie.898

ISSN: 2115-6395

Editor

Association ESCAL

Referencia electrónica

Marta Penhos, «Entretien avec Leonel Luna. Paisaje Americano, exposición de Leonel Luna », Artelogie [En línea], 10 | 2017, Publicado el 05 abril 2017, consultado el 15 septiembre 2020. URL : http:// journals.openedition.org/artelogie/898

Este documento fue generado automáticamente el 15 septiembre 2020.

Association ESCAL 


\title{
Entretien avec Leonel Luna. Paisaje Americano, exposición de Leonel Luna
}

\author{
Pabellón de las Artes, Universidad Católica Argentina, Buenos Aires, \\ 07/09/16 al 09/10/16
}

\section{Marta Penhos}

1 Los puentes entre el arte contemporáneo y las imágenes, que como capas geológicas, vienen sedimentando en nuestro universo visual desde épocas remotas, son cada vez más frecuentes y adquieren diversas formas y modalidades. La cita explícita, la apropiación y la reelaboración de obras canónicas de la historia del arte son recursos corrientes utilizados por muchos artistas del siglo XXI. En la escena artística argentina, la muestra retrospectiva de León Ferrari de 2004 puso en evidencia, en el debate que involucró a amplios sectores de la sociedad y en las agresiones a las piezas exhibidas, la contundencia crítica y estética que puede alcanzar el trabajo con obras del pasado, tan auráticas como el Juicio Final de Miguel Ángel. En una clave distinta, centrada en el humor no exento de reflexión, Alberto Passolini ha producido desde hace varios años pinturas en las que revierte o trastorna el sentido inicial de aquellas que le sirven de inspiración, como sucede con "Malona”, la contracara, en cuanto al género, de "La vuelta del malón”, de Ángel Della Valle, de 1892.

2 Y es justamente el siglo XIX, la etapa en que se constituye el campo artístico en la Argentina, cuando confluyen en este territorio artistas extranjeros en busca de nuevos temas de inspiración, y artistas locales, muchos de ellos formados en Europa e impulsados a construir un "arte nacional", donde abreva Leonel Luna para llevar adelante un programa que comienza a delinearse con el despuntar de los años 2000. Producidas en plena crisis política, social y económica algunas de sus obras traen de un modo muy personal el imaginario decimonónico al presente. Los piqueteros que impiden el paso de los autos en "Piquete en los bajíos de Barragán" (2001) son los nuevos bárbaros enfrentados a una civilización que los ha marginado y estigmatizado. Y las pinturas de Prilidiano Pueyrredón de la década de 1860, que muestran un plácido 
descanso durante una travesía en las afueras de Buenos Aires, con los personajes ubicados en un paisaje que disimula la monotonía de la llanura, se transforman en "Un alto en el campo" (2001) en la versión cotidiana del tránsito por esas inmensidades. El rancho destartalado, las viejas camionetas y el improvisado almuerzo bajo el ombú, ícono del paisaje pampeano, nos permiten asomarnos a una de las características de la obra de Luna: su mirada cómplice, exenta de conmiseración, sobre los protagonistas de sus composiciones, seres del común, obreros, desocupados, cartoneros.

Con estos antecedentes, la exposición Paisaje americano es, de acuerdo a las palabras del artista, un proyecto en el que recoge sus experiencias de varios años para darle una forma integrada. Si el paisaje es para Luna una idea que se transforma continuamente, el adjetivo "americano" abre a una reflexión sobre los modos de pensarnos en relación a geografías, territorios y lugares. Las obras que integran la muestra son, sin duda, paisajes, espacios a contemplar pero también y sobre todo, espacios habitados, transitados, usados. $Y$ es por esto que las figuras que encontramos en ellos adquieren un papel fundamental, como sucede en "Canto al trabajo", inspirado en el conjunto escultórico de Rogelio Yrurtia (1922), donde un grupo de cartoneros, usualmente subsumidos en el paisaje urbano, sin personalidad que los destaque, adquieren relevancia y son la clave local y actual que resignifica la obra original. De manera similar, entre los migrantes que enarbolan la bandera norteamericana, actores anónimos de una épica contemporánea, algunos nos miran, apelándonos a darles una identidad, distinta a la de los héroes de "Washington cruzando el río Delaware" de Emanuel Gottlieb Leutze (1851), pintura icónica de la historia de los EEUU que Luna reelabora, actualizándola.

Esas personas, que Leonel registra en la calle o en algún viaje y luego convierte en verdaderos protagonistas, abren para los espectadores el paisaje, se lo muestran, orientándolos en un sentido que luego cada uno puede adoptar, completar o cambiar de acuerdo a su propia percepción y experiencia.

Es clara la fascinación del artista por los viajeros del siglo XIX. Es así que en 2002 realizó una serie sobre el relato del cautiverio del francés Auguste Guinnard entre los indígenas de la pampa. En Paisaje americano una obra resume y concentra ese interés por referir a una de las figuras más sobresalientes de la ciencia y la literatura occidentales: Alexander von Humboldt, quien inauguró un modo de concebir y representar el paisaje de nuestro continente que se constituyó en un modelo de larga data. La complementación de datos científicos y experiencia subjetiva alimentó el arte y la literatura producida por otros europeos que seguían sus pasos, como Rugendas, Berg, Bellerman, y el norteamericano Church, y también por los propios americanos decimonónicos que, en mayor o menor grado, se pensaron y representaron de acuerdo con los lineamientos humboldtianos. Entre los varios retratos de Humboldt, uno tuvo especial fortuna, aunque el sabio lo rechazó por su fantasiosa elaboración de hechos sucedidos muchos años antes. "Alexander von Humboldt y Aimé Bonpland en su choza en la selva" de Eduard Ender (1856) se transforma, en la obra de Luna, en una escena cotidiana, "Vida de campo". Cambiando la choza por un galpón, y el exuberante paisaje de fondo por una sencilla vista campestre, el artista ubica a su padre, quien adopta un aire de siesta más que de elucubración científica, en el lugar de Humboldt. La madre, como Bonpland, ordena y "clasifica" las verduras que desbordan, igual que en la pintura, la "mesa de trabajo". Con amoroso humor, Luna nos muestra que el paisaje puede ser la invención de una mirada ajena, como la de aquellos viajeros, pero es 
también el lugar de los afectos y las memorias, un espacio que se vive, se palpa y se construye todos los días.

6 La mayor parte de las obras de Leonel son producto de procedimientos en los que interviene la fotografía digital, la pintura y el montaje. Pero para "Límites", una impresionante representación de los Andes, eligió la pintura sobre vinilo y un formato apaisado de gran tamaño que recuerda los panoramas de los artistas de la Escuela del Río Hudson. Las montañas, protagonistas de la ciencia y el arte del s. XIX, son límites que marcan fronteras pero que también se desean cruzar. En aquellos tiempos eran desafíos para el viajero, como el mismo Humboldt cuando asciende el Chimborazo poniendo a prueba su resistencia física, y uan inspiración para el artista, como Friedrich que se representa en la cima, dominando con su vista todo lo que lo rodea. Los Andes de Luna son una de las estrellas de la exposición, porque disparan infinitas asociaciones con momentos de nuestra historia y porque nos ponen frente a lo sublime: un puente que nos conecta, desde el presente, con un pasado vivo.

\section{Leonel Luna, Canto al trabajo}

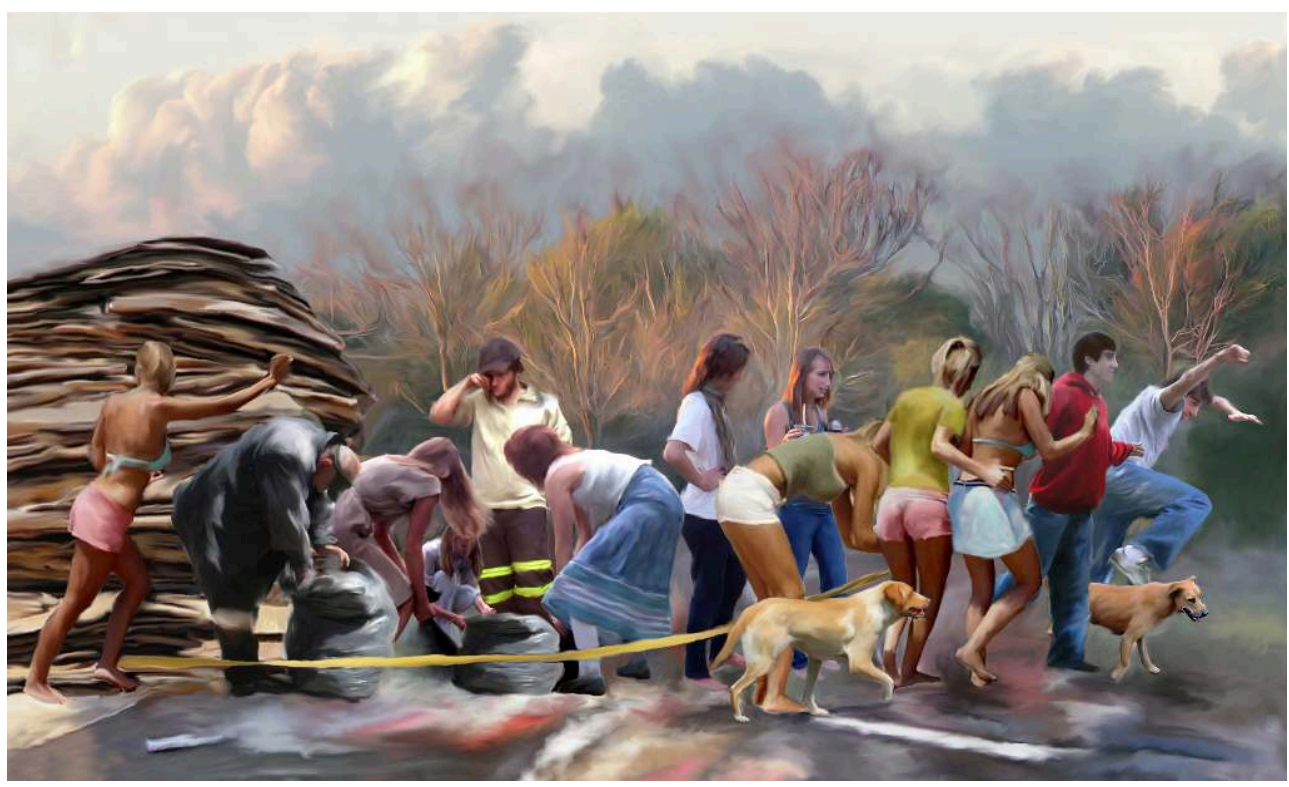

Impresión mixta 1/1, 180 × 300 cm 


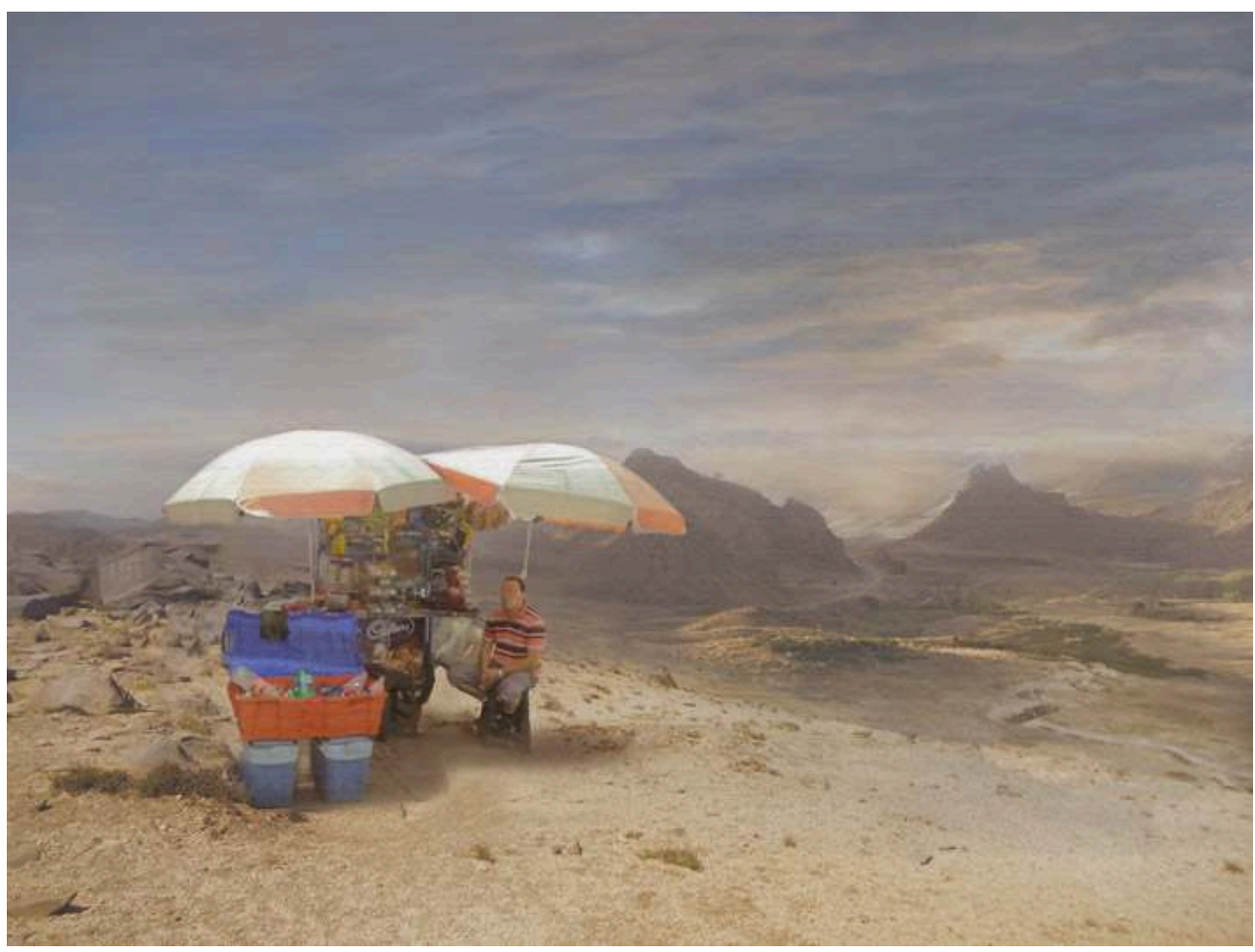

Impresión s/ papel de algodón ed. 1/5, 58 cm x 44 cm

\section{Leonel Luna, La pesca sel sol, 2016}

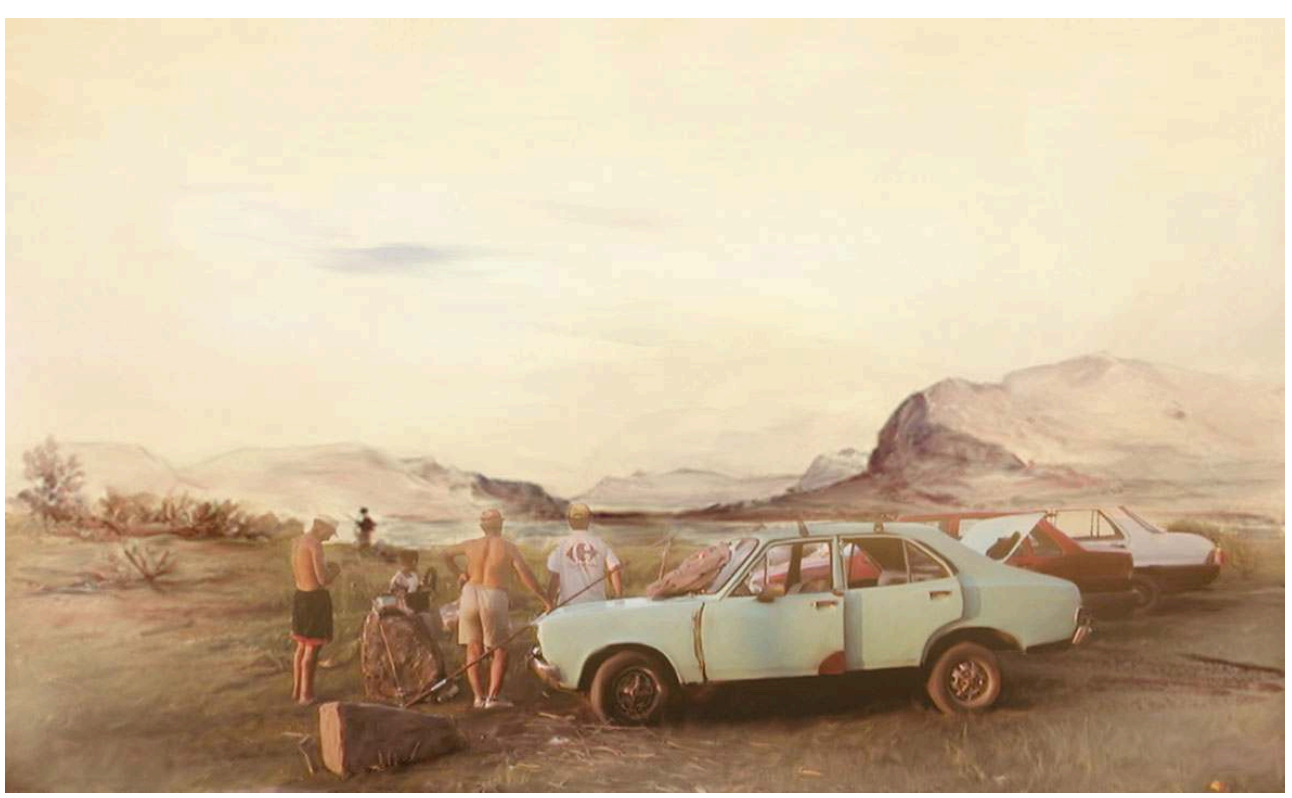

Impresión s/ papel de algodon ed 1/5; 42 × $70 \mathrm{~cm}$ 
Leonel Luna, Sueño americano

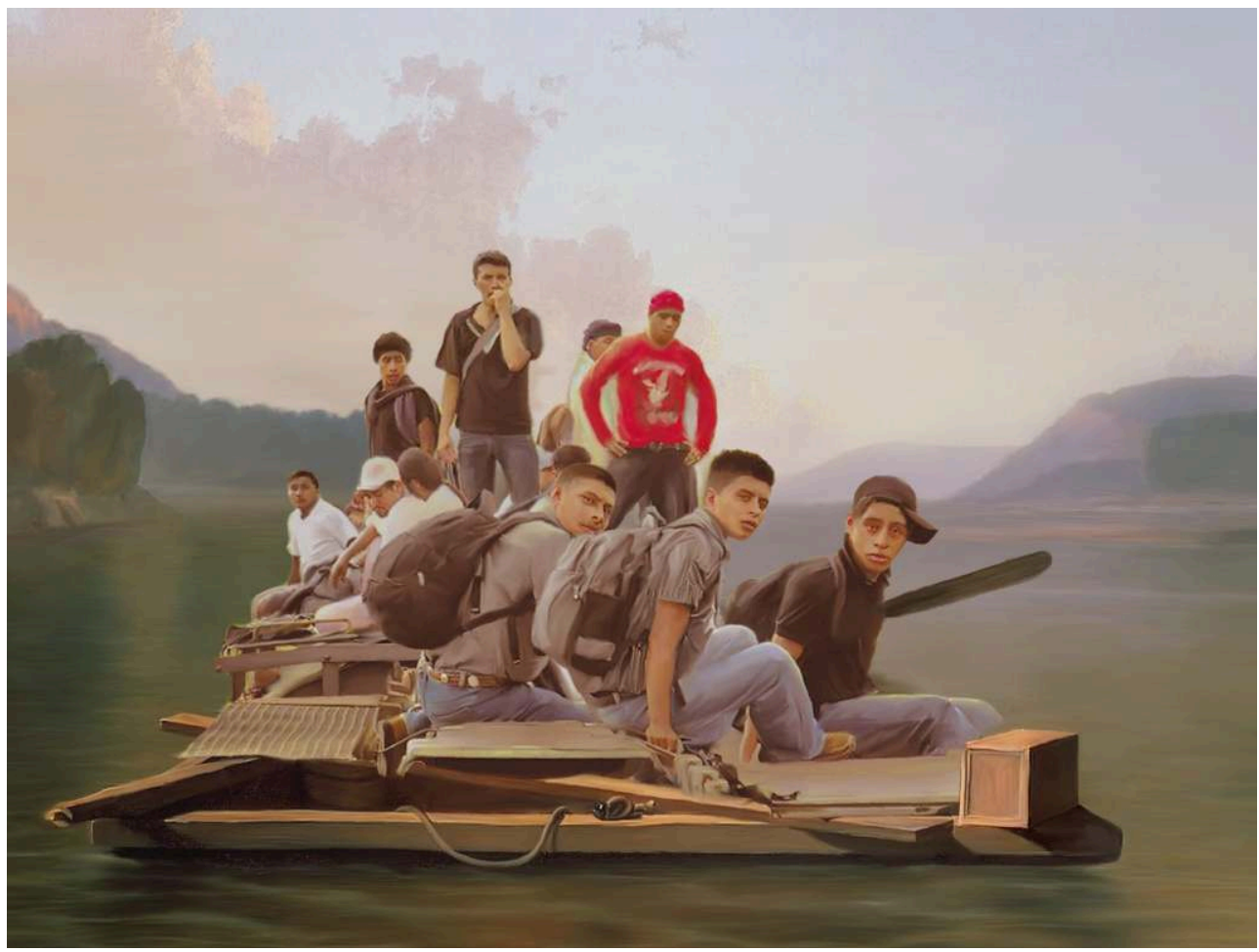

Impresión sobre vinilo, 190 × 135 cm

Leonel Luna, Vida de campo, 2012

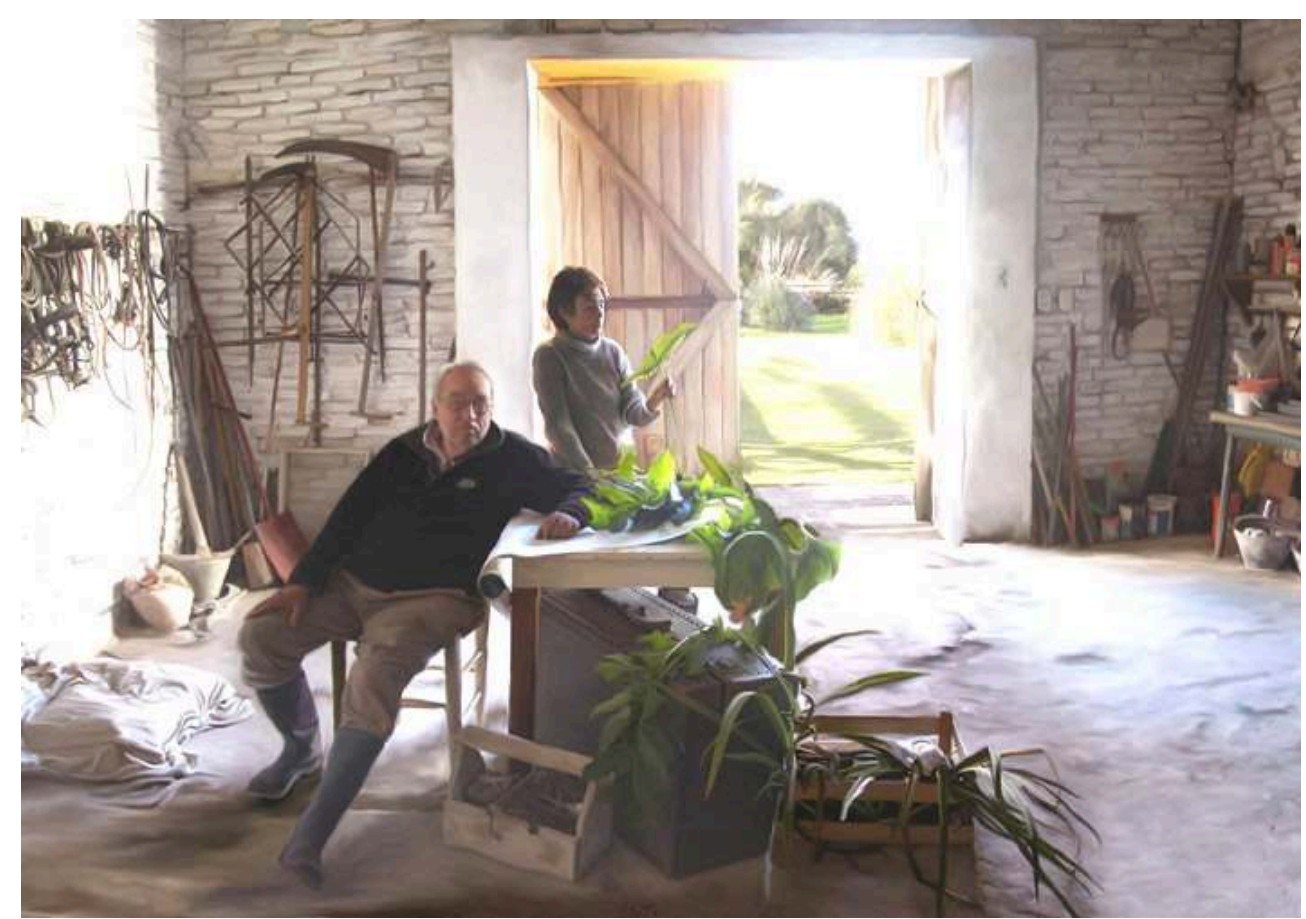

Impresión mixta y lapiz sobre tela. ed 1/ 1, 100 × 75 cm 
Este medio no se puede ver aquí. Por favor refiérase a la edición en línea http:// journals.openedition.org/artelogie/898 